\title{
My Rhetorical Situations and Discourse Communities
}

\author{
Rigvi Kumar ${ }^{1}$ \\ Writing across the University of Alberta, $2021^{2}$ \\ Volume 2, pp. 25-28 \\ Published December 2021 \\ Keywords: rhetorical situations, discourse communities, genre
}

Before reading a prompt for one of my papers in a Writing Studies course, I never imagined how rhetorical situations could shape and define a person's writing in many ways. Rhetorical situations presented by discourse communities prompt a writer to create pieces of writing in response to their established norms, needs and goals. My affiliation with two different discourse communities determined if I wrote like a mindless undergrad or a competent, know-it-all corporate trainer.

Usually, the rhetorical situation in my English literature classes revolved around writing research papers, literary reviews, or summaries of literary texts. The genres became the primary methods used by the English literature discourse community as textual tools aimed to evoke critical thinking and analytical skills with regard to certain texts as objects of study. These genres asked students to either observe a recurrent theme in a text - for example, issues about gender and sexual identity - or interact with the text as a whole. Generally, the topic of choice and the genre of writing were rather consistent with the goals of the English literary community. For instance, a topic presented in my Medieval English class asked us to disguise [and] analyze the function of disguise in Fantomina by formulating an argument about the significance of disguise to the gender politics of the text.

The appropriacy of such topics and forms of writing function well within the community as the primary goal of the topic is to prompt an analytical inquiry into the text. Certain verbs like "analyse" and "criticize" are examples of the specified lexical terminology used primarily as discoursal conventions. After my encounter with these terms over and over, I started to wonder what it means to critically analyze? Furthermore, is my writing critical enough? I felt that the term critical analysis is a fluid and abstract element in itself.

${ }^{1}$ Correspondence: Rigvi Kumar (igigi@ualberta.ca)

${ }^{2}$ Writing across the University of Alberta (WAUA) publishes undergraduate student writing from Writing Studies courses at the University of Alberta. You can find WAUA online at writingacrossuofa.ca. 
As an English student, my writing revolved around solely analyzing a text; however, despite my conscious efforts, the final product always seemed rather superficial and incomplete. As a member of the English literature discourse community, I felt that my inability to communicate with the members stemmed from my lack of knowledge of the requirements of the discourse. I was missing the necessary skills related to writing in humanities as a discipline, and the rhetorical strategies on approaching and writing a text. I remember procrastinating and not finishing assignments until a few days before the deadline because I didn't feel motivated to write on a text because the idea of analyzing everything seemed rather high level and abstract. It felt as though I was asked to keep digging into the ground in hopes of finding the earth's core despite knowing that I was predestined to fail. Similarly, to keep dissecting a text in hopes of adequately providing an analysis seemed futile. It felt as though I was superimposing meaning (by critically analyzing it) in hopes of creating ideas that were superficial in nature. There was a sense of reluctance in doing the actual writing because the pedagogical aim of the discourse community prioritized the writing product instead of the writing process. I believe that the English literature community uses its "participatory mechanism primarily to [simply] provide information and feedback" about literature. It doesn't encourage the members to develop rhetorical skills and, in turn, use those skills to set up better means of intercommunication (Swales 472).

Furthermore, the English literature community doesn't disseminate knowledge about the art of writing or rhetoric. I feel that my lack of understanding of rhetoric led to my downfall and loss of a sense of confidence in writing. My focus remained largely on constructing an ornamented or pretentious argument in the name of literary criticism or analysis. Primary focusing on the linguistic features of the text prevented me from understanding the real portrayal of rhetoric as a "study and practice of shaping content" (Covino and Jolliffe 4). I think it's incredibly difficult to shape a piece of writing without appreciating the process of writing and understanding that it's for a purpose. English professors don't tend to discuss rhetoric, for instance, as a way to present ideas and yet we were magically supposed to know about it and use it in our writing as a way of shaping our content and ideas. The learning outcomes of tasks or assignments seemed baseless because the writing itself was void of the basic understanding of rhetoric. The idea of critically analyzing a text seemed rather vague as basic guidance and support about how to approach a text through a critical and analytical lens were not provided. Analyzing a text became a form of routine behaviour expected of students in the community, and those who failed to comply with the criteria unconsciously became marginalized members of the community.

My rhetorical situation as a corporate trainer was completely the opposite. My writing revolved around designing and implementing handouts and summaries, which were 
like itinerary checklists or schedules, for training and orientation sessions. For instance, when onboarding newly hired employees, it is incredibly important to give a detailed set of guidelines of the goals of training sessions and the skills which they'll learn during the orientation. Although, there were employee handbooks to guide me in establishing a handout (which I gave to the trainees at the start of the session), the details containing, which skills they would learn and how much time would be spent on teaching them, differed in each training session. Therefore, in writing or planning my training sessions, I would consider these basic necessities as the basis of generating ideas about the training schedule and timeline for the day. Unlike writing for the English discourse community, the basic knowledge in conducting an orientation session is easily accessible. The genre of writing and designing an orientation handout also seemed rather automatic as the goals were real and not hypothetical or abstract. For instance, a cashier's responsibility can be pictured and imagined easily because it is based on the execution of real tasks, whereas the task of critically analyzing an 18th-century novel or text is rather hypothetical and somewhat imaginary.

In this sense, writing a training handout or planning out a schedule seemed easier because the skills outlined were automatic. It was also easier to write a handout for an orientation rather than an academic paper because there was no fear of authority or the supreme (in this case, my audience who was my professor). My audience had an ample amount of knowledge on the topic; therefore, it became an intimidating task to persuade my professor knowing that they were an expert in the field. Approaching an audience on a subject or topic about which their knowledge is greater than the rhetor's is an intensively fearsome task. Furthermore, even if I were able to generate good ideas, I didn't know how to convert my thoughts from simple words to a well-constructed, and highly performative piece of writing.

Throughout my academic years, I felt a sense of shame in presenting my writing because it felt incomplete, void of ideas, and lacking. The expectations of the discourse community that consistently ask the members for an analysis of a text prevented me from assimilating into the community. In this sense, I wonder if the discourse community of English literature was really successful in getting students, like me, to think about the text with a critical and analytical lens. I believe that members of the English literature community could benefit greatly from knowledge on rhetoric, as it would enable them to shape and reinforce their ideas and content. I believe that by creating an awareness of some concepts used in the Writing Studies discourse (for instance, rhetoric or the writing process), the English literature community could significantly help its members in producing work that aligns with their goals. 


\section{Works Cited}

Swales, John. "The Concept of Discourse Community." Writing about Writing: a College Reader, edited by Elizabeth Wardle and Doug Downs, Bedford/St. Martins, 2014, pp. 215-229.

(c) $(\bigoplus$ This work is licensed under CC BY-NC-ND 4.0. To view a copy of this license, visit https://creativecommons.org/licenses/by-nc-nd/4.0. 